\title{
Gatherers of central Poland: a field study
}

\author{
By Tomasz Rakowski (University of Warsaw)
}

This paper concerns the way in which poor inhabitants of a rapidly industrialized terrain in central Poland gather and collect different sort of waste. Such phenomena as dwelling by using gathered scrap and any industrial waste serve as a field for an anthropological study. One the one hand the gathering is a certain strategy of surviving. On the other these collected things create a kind of a narrative - the objects anchor the gatherers experience, write down their biographies and reveal their relation to the local social and economic life.

\section{Introduction}

New poverty in Poland became noticeable after the transformation of the 1990s and was usually connected with the collapse of the state's rural enterprises and industrial centers (Tarkowska and Sikorska 1998, Tarkowska 2001). Nevertheless, the poor settlements situated near the Bełchatów lignite mine in central Poland - the biggest mining settlements in Poland and the subject of my research-seem somewhat strange. They remain hidden, even if they have recently become more noticeable in the landscape, as the district is now known as one of the richest and best-organized in the country. Remaining outside the public investment and decision-making channels, the settlements illustrate the process of marginalisation and social exclusion of the poor in a relatively rich world (Washington, Paylor and Harris 2000). A modern bicycle path goes on for kilometers between the villages, where people often use their bicycles to carry gathered scrap metal and gum waste.

People whom I was talking to, the inhabitants of poor households set on the edge of the mine, experience the transformation and development of the district in a particular way. Their world-view seems to be related to their day-to-day practice of gathering various sorts of waste. On the one hand the gathering is a strategy for surviving under conditions of scarcity and poverty: the inhabitants of these places live off gathering scrap, gum waste and any other waste that the mine produces. On the other hand this is a certain way of collecting things - these objects write down biographies, anchor experience and reveal, in a particular way, their relation to the local social and economic life. Such phenomena as living and dwelling by and through using gathered scrap and any industrial waste served as the specific terrain for my ethnographic fieldwork.

\section{Gatherers: the mine}

In the 1970s, the rural area in central Poland located around the town Bełchatów was a poor region with no industry. The communist government did not promote any perspective of 'development' or 'progress'. The inhabitants looked for jobs in other industrial centers, such as Łódź and Górny Śląsk. In the mid-70s, after the discovery 
of coal fields, a great enterprise was established in the region. The Bełchatów lignite mine became the pride of the state. Layers of soil disappeared, eaten by gigantic machines, and the greatest conventional power-station in central Europe was built near the lignite mine in a very short amount of time. People from all over the country started to move to the region. Blocks of flats and great chimneys rose and the expansion of industry seriously changed the countryside. The biggest social promotion of the People's Republic took place in the region while the rest of the country was immersed in deep stagnation.

A kind of a game ensued between the enterprise and the villagers around the Bełchatów quarry. The company paid a lot for the farmers' land when the mine needed new areas. Many families waited for that moment. To get more money from the company, some of them tried to upgrade their households by planting new trees or pretending that they had installed a new heating system. Finally, some of them were lucky and got a significant amount of money, with which they could buy new flats in the town. Some of them were not so lucky, as the company didn't need their land and they stayed in ruined households. Very often they became excluded from the official circulation of investments during the following years. At present, such poor settlements surround the industrial zone. The inhabitants of the households have taken up activities which are partly illegal: they collect the companies' secretions such as used ropes, gum waste, and hundreds of kilos of scrap. In addition, they play with and cheat the company guards. The comments that I listened to during my fieldwork contain characteristic ambiguities: powerlessness and resignation are mixed with a sense of peculiar power, as for instance evoked by the knowledge of secret entrances to the zone or acquaintance with the security service. There are conversations, complaints, and new mythologies: a never-ending testimony. The memories and comments that I collected during my fieldwork, conducted in the years 2002-2004, are the core of this study.

The task I set myself in the field was to observe and describe these specific practices of gathering and collecting. After a few weeks of research I realized that the objects the inhabitants find on the waste dump are sorted and displayed inside their homes and backyards, where one could find used, rusty heaters as well as single parts, animal trophies, metal dishes and industrial tools. There are also small huts where other objects are gathered: metal nets, pots, springs and various pipes. In one house there was a small shelf looking like an altar with a few mirrors, rusted electric engines and old coils. A few of those things have, at least potentially, a value as useful items. I spontaneously thought that a particular sense of museums was being evoked and presented, as people organised a kind of private museums or cabinets similar to the cabinets of curiosities that appeared in Europe in the sixteenth and seventeenth centuries (Pomian 1990). The objects gathered in these private cabinets and museums were usually things without practical usefulness, as Pomian argues; having lost their day-to-day function, sundials, pictures, coins, sea shells, fossils, and various eggs had been changed into containers of meaning, semiophors (Pomian's term). Here I am using the term 'museum' because I treat these gathered and stored objects as a kind of microcosm of meanings, where the particular world-view of my informants is condensed and revealed.

As previously mentioned the practice concerns the people living outside the boundaries of the official economic life. They used to be peasants and mine workers; nowadays they are long-term unemployed living on dried and polluted fields. They have been cut off from the mine for various reasons, thus living outside the most 
desired place of work and cut off from a local source of every prestige and every privilege. Yet, being excluded from that place they still gather its waste, its objects. For more than ten years, aided by a little luck, they have been taking steel ropes, rolls of gum, cables made of copper, and heavy screws.

\section{Collecting: the hidden knowledge}

The first thing I noticed during my fieldwork was that when my interlocutors talked about how they gathered and collected, it often turned out that this activity required almost no struggle, no effort. Finding the objects sometimes seemed to be very easy and accidental, and not the effect of planned, thorough exploration. They often stressed the ease of the exploratory process as well as the fact that the waste dump contains almost everything they need. I observed that they often used the original workwear of the mine workers, with its emblems, found on the dump. People told me they had found an almost new sofa, a pair of good shoes, an old wardrobe, and enamel pots. Some of them stressed that the most interesting and valuable things were found accidentally and without any effort at all. I was told a few times that my informantswhile coming back from the dump, taking the shortcut - had found something which they considered to be a radiation-measuring instrument. I also heard that they had found a steel rope lying below a crushed block, and a roll of gum and quite good metal sheets hidden under the coal dust. 'All of that is lying around and wasting,' they would say, 'they [i.e. the mine] throw it away, because they want to get rid of their problem, here, sometimes when you just bend you can find everything you need, everything may suddenly appear'. These stories about how they find their objects, their treasure, and their curious scrap, have a particular feature: the inner world of the mine seems to reappear. With these objects the mine and the privilege that comes with it seems to fall directly into their hands.

Then there are also secret and mysterious objects found by the gatherers at the waste dump, such as packs of unknown drugs, strange electronic devices, and something that they consider to be 'radioactive materials'. During the course of my fieldwork it came to seem as if, through this collecting activity, they achieved a certain access, namely access to the most hidden knowledge of the place, the knowledge that is out of reach for others. In their work on the dump, one might say that dark and forgotten issues surrounding the mine's activity are revealed. The area itself, as one of them explained, is probably a kind of experimental field where 'human reactions to radiation and other factors were being measured'. 'The drugs,' I was told once, 'were probably tested on the mine workers'. And furthermore: 'everything that happens around here is one of the biggest hidden experiments in this part of Europe'. Thus, they became somehow the keepers of the mine's secrets and the witnesses of its crimes and offences. And then their relation to the mine, or their way of communicating with it, became more intimate than I would ever have expected: they seemed to possess the knowledge that even police and local authorities had never been able to reach. The objects that they found turned into trophies in the literal sense of the term. They were often exhibited in their homes in a special and conspicuous place - teeth of wild pigs, for instance, which were said to live and graze on the mine waste, were put on the shelf above the television, 'secret documents' were attached to a calendar, and an object which was believed to be a prototype of the 'Geiger counter' was placed in a corner of the living room. My informants seemed to attach particular significance to the objects. 
At the same time, they did not, to the extent that I would have expected, care to prove or disprove their theses explaining their discoveries. While my interlocutors bragged about their access to hidden knowledge or to secret privileges, they knew well enough that this was not a serious activity. They used the gum waste for heating their homes, but of course everybody realized that this was not such a big advantage at all. During our conversations their objects were often referred to as mess, rubbish, and so on.

What is this collecting and gathering all about then? What is its function? In general I would say that this practice has at least three dimensions. Firstly, it enables the gatherers to obtain money and means to survive. They sell the scrap, heat their houses with gum waste, and construct useful self-made devices and various tools. Secondly, they create their private museums, cabinets of curiosities, which is the focus of my fieldwork. Thirdly, this is a specific practice which provides the opportunity for participation in the local circulation of goods as well as in a social environment - they seem to 'join' the mine through playing a particular game with the guards and authorities. This is an attempt to take part in the world they have been excluded from, and which is so close that they cannot turn their backs on it.

\section{Representation: the wild objects}

In the sixteenth and seventeenth centuries, when the New World appeared, the modern museum was also born. At that time curiosities of exotic, overseas fauna and flora, as well as various masks and fetishes, became subjects of collecting and gathering (Clifford 1988:215-222). The world that was being presented was organized around one axis and, because of that, started to submit to the mechanisms of representation. This way of exhibiting was directly related to the European tradition in which the distance between the thing or representation and the reality was a negative value, a kind of obstacle. From this perspective, the question was: how can we reduce that remoteness? How can we get through that distance? This was a fundamental problem not only for philosophers, but for the modern collectors as well. It was a question which, from the seventeenth century onwards, accompanied the collections made up of objects of art, handicrafts and overseas curiosities. While successive terrae incognitae such as the Antilles or the Great Plains appeared on the world map, the number of cabinets and museums gathering their curiosities exploded on the Old Continent. While we all know that the objects, the wild things, have never lost their autonomy and otherness, the point is still that these objects were arranged in a particular space and particular context. Thanks to this particular language of the museum, the objects became elements of a domesticated, private and somehow safe landscape, and therefore the world they represented could lose its frightening otherness.

Here, I hypothesize that the key function of the collections found during my fieldwork - similar to the function of the modern collections brought from the New World - is an impossible, realistically speaking, attempt at assimilating the inaccessible world. Obviously this is not only about the very sense of possessing, which has also been characteristic of the above-mentioned European collectors and gatherers. Rather, it is about a sphere in which my interlocutors try to reduce their distance to the enterprise, the remote world, thanks to the gathered and collected objects. These objects seem to have the important function of aiding conceptualization of a presently inconceivable reality - the reality of the mine, of welfare and long-term unemployment, and of the neighboring environment. 


\section{Amateurs: a passion}

In conclusion, my guiding question has been: What do we find, then, in these specific collections anchored at the edge of the great mine? Why do these objects fill these houses and their backyards, while being used as everyday tools, materials or as a source of income? The very problem is that these people seem to know quite well that they are the collectors of facts that could never have taken place. They do not treat their theories as absolute truths: our conversations often involved occasional pauses, indicating embarrassment at the more improbable stories. They know well, I may say, that they collect facts and knowledge that no one will ever ask about or be interested in. In a way they act like amateurs. One of my closest informants once showed me his collection and pointed to a stump of 'the radioactive tree' that he found some time ago. 'My secret passion is archeology', he told me then. He is to a degree an archeologist-amateur, due to the fact that the mine with its secrets is, so to speak, right in his home, on its walls, in the backyard, in his garden shed. But this is a completely reversed representation. The very expression of his collection, besides this sudden access to a represented world (the mine) is, in fact, an irreducible distance, a certain lack. By this I mean that the collection expresses his own absence in the mine, in Bełchatów, which he visited last time a year ago, and which also represents his absence in the district's circulation of goods and privileges. And this is a particular self-narrative strategy. A gum-made belt, obscure devices, and electric transformers are witnesses of the facts of the ongoing modernization, which is still changing everything around him. 'The mine with its secrets and wealth,' the collected objects seem to say, 'is here, close at hand, which means just as much that you cannot reach it.'

\section{References}

Bełchatów Lignite Mine. 2000. The Monograph. Bełchatów: Bełchatów Lignite Mine Publications.

Clifford, J. 1988. On collecting art and culture. In his The Predicament of Culture. Twentieth-Century Ethnography, Literature and Art. Cambridge, Massachusetts and London: Harvard University Press.

Pomian, K. 1990. Collectors and Curiosities: Paris and Venice 1500-1800. Cambridge: Polity Press.

Tarkowska, E. 2001. An underclass without ethnicity: the poverty of Polish women and agricultural laborers. In Poverty, Ethnicity and Gender During the Market Transition (eds) R. Emigh and I. Szelenyi, 83-122. Westport, Conn.: Praeger.

Tarkowska, E. and J. Sikorska. 1998. Social history of poverty: Polish experiences and research perspectives. East Central Europe Special Issue 20-23, 171180.

Washington, J., I. Paylor and J. Harris. 2000. Poverty studies in Europe and the evolution of the concept of social exclusion. In Experiencing Poverty (eds) J. Bradshaw and R. Sainsbury, 263-283. Aldershot: Ashgate Publishing Company. 


\section{About the author}

Tomasz Rakowski studied ethnology and cultural anthropology at the University of Warsaw (Poland), and at present he stands as a doctorate student at the Institute of Polish Culture at the University of Warsaw. He is about to finish his $\mathrm{PhD}$ dissertation, entitled: 'The anthropologist as a poverty visitor; Polish economic transition and the culture of powerlessness'. He has carried out fieldwork in the rapidly de-industrialised regions in Poland and in northern Mongolia (Hovsgol). He is also a medical doctor, graduated at the Medical University of Warsaw and working at the Emergency Unit. He can be contacted at tomaszrak@,o2.pl 